Bulletin d'études orientales

LXIV | 2016

Histoire et anthropologie des odeurs en terre d'Islam à l'époque médiévale - Année 2015

\title{
Hommes, femmes, parfums et puanteurs dans quelques textes littéraires arabes des $\mathrm{IV}^{\mathrm{e}} / \mathrm{X}^{\mathrm{e}}$ et $\mathrm{V}^{\mathrm{e}} /$ $\mathrm{XI}^{\mathrm{e}}$ siècles
}

Monica Balda - Tillier

\section{OpenEdition}

\section{Journals}

Édition électronique

URL : http://journals.openedition.org/beo/4669

DOI : $10.4000 /$ beo.4669

ISSN : 2077-4079

Éditeur

Presses de l'Institut français du Proche-Orient

Édition imprimée

Date de publication : 1 avril 2016

Pagination : 249-264

ISBN : 978-2-35159-800-9

ISSN : 0253-1623

Référence électronique

Monica Balda - Tillier, "Hommes, femmes, parfums et puanteurs dans quelques textes littéraires arabes des IVe/ $/ X^{e}$ et Ve/XI siècles », Bulletin d'études orientales [En ligne], LXIV | 2016, mis en ligne le 01 avril 2018, consulté le 04 mai 2019. URL : http://journals.openedition.org/beo/4669 ; DOI : 10.4000/ beo.4669 


\section{Hommes, femmes, parfums et puanteurs dans quelques textes littéraires arabes des $\mathrm{IV}^{\mathrm{e}} / \mathrm{X}^{\mathrm{e}}$ et $\mathrm{V}^{\mathrm{e}} / \mathrm{XI}^{\mathrm{e}}$ siècles}

Monica BALDA-TILLIER

Résumé : L'odorat jouit d'un statut privilégié dans la culture arabe médiévale. Dans certains textes littéraires des $\mathrm{IV}^{\mathrm{e}} / \mathrm{x}^{\mathrm{e}}$ et $\mathrm{V}^{\mathrm{e}} / \mathrm{XI}^{\mathrm{e}}$ siècles, les parfums et les puanteurs revêtent une valeur morale ou une connotation socioculturelle particulière. Cet article est une étude, nonexhaustive, de l'imaginaire et des significations sociales attribuées aux odeurs à cette période.

Mots-clés : Odeurs, parfums, puanteurs, littérature arabe médiévale, raffinement, mujūn.

Abstract: Smell has a privileged status in the medieval Arab culture. In some Arabic literary texts of the fourth/tenth and fifth/eleventh centuries, perfumes and stinks reveal moral values or take peculiar socio-cultural connotations. This article represents a study, which does not claim to be exhaustive, of imagination and social meanings that classical literary documents attributed to odors at that time.

Keywords: Odors, perfumes, stinks, medieval Arabic literature, refinement, mujūn.

$$
\begin{aligned}
& \text { ملخص : الرائحة لها وضع متميز في الثقافة العربية في القرون الوسطى . تشير بعض النصوص الأدبية القبا }
\end{aligned}
$$

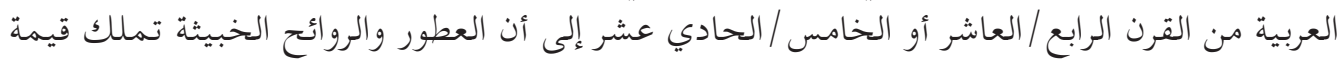

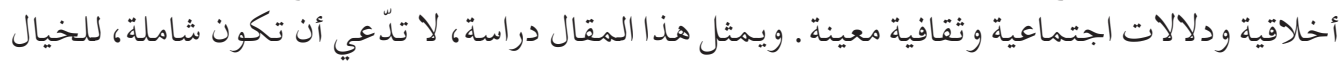

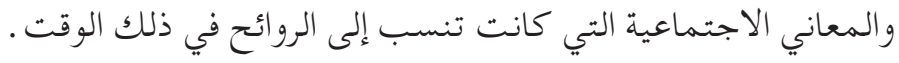

$$
\begin{aligned}
& \text { الكلمات المحوريّة : روائح، عطور، نتونة، الأدب العربي القديم، ظرف مجون . }
\end{aligned}
$$


Souvent méprisé dans les sociétés occidentales, où il fit figure de « résidu archaïque de la bête en l'homme " ${ }^{1}$, en particulier lorsqu'on le compare au bien plus «noble » sens de la vue, l'odorat jouit d'un statut privilégié dans la culture arabe médiévale imprégnée d'islam. Cette religion lui attribue en effet une valeur eschatologique particulière : " the sweet smell of a martyr is a clear indication that this pure soul had bypassed the torments of the grave and gone directly to Paradise. [...]. The scent of martyrs, often compared with the fruits of Paradise, intimated the comforting closeness of the Garden. ${ }^{2}$ "

Ce n'est pourtant pas de l'odeur de sainteté dont nous traitons dans cet article, mais de senteurs beaucoup plus terrestres. Partant de l'observation que, dans certains textes littéraires arabes $\mathrm{du} \mathrm{IV} / \mathrm{X}^{\mathrm{e}}$ et $\mathrm{V}^{\mathrm{e}} / \mathrm{XI}^{\mathrm{e}}$ siècles, les parfums et les puanteurs revêtent une valeur morale ou une connotation socioculturelle particulière, ce travail représente une étude, qui ne prétend pas à l'exhaustivité, des significations que l'on attribuait aux odeurs à cette période. Pour un objet aussi volatil que les odeurs, ce sont principalement les documents écrits, et les textes littéraires en particulier, qui nous donnent accès à l'« imaginaire social » de l'odorat 3 .

Notre démarche consiste à relever et à classer les mots ou les expressions désignant les odeurs, bonnes ou mauvaises, dans des ouvrages où elles sont utilisées pour dénigrer ou, au contraire, faire l'éloge de la beauté et du raffinement, et deviennent ainsi des marqueurs socioculturels d'identité.

Le Kitāb al-Muwaššā (Le livre du brocard), connu aussi sous le nom de Kitāb al-Ẓarf wa-l-zurafā' (Livre du raffinement et des raffinés) d'al-Waššă' (m 325/937) ${ }^{4}$, a été choisi comme point de départ pour traiter des parfums. Tout en faisant partie du genre littéraire des traités d'amour, qui fixent les préceptes, la philosophie et les règles à suivre de l'ars amandi 'udrite, cet ouvrage se situe à part. En effet, outre les éléments caractéristiques du genre, comme la description des états des amants et de l'essence de l'amour, il définit un code de comportement en société. Il représente un véritable guide de conventions sociales d'élégance à l'usage des raffinés, réglementant, dans le même temps, les mœurs auxquelles les membres de ce groupe social d'élite doivent se conformer ${ }^{5}$.

Les données recueillies dans le Kitāb al-Muwašša ont ensuite été confrontées à un deuxième ouvrage, intitulé Kitāb al-Muhibb wa-l-maḥbūb wa-l-mašmūm wa-l-mašrūb (Livre de l'amant, de l'aimé, des senteurs et des boissons) d'al-Sarī al-Raffā' (m. v. 362/972) ${ }^{6}$, une anthologie

1. JACQUET 2010, p. 30.

2. EVANS 2002, p. 194.

3. Nous avons repris l'expression « imaginaire social », que nous avons mise entre guillemets, de l'ouvrage d'Alain Corbin, Le miasme et la jonquille (CORBIN 2008).

4. Al-Waššā', Kitāb al-Muwaššā L' Lauteur du Kitāb al-Muwaššāa, le grammairien et lexicographe originaire de Bagdad al-Waššă', fut reconnu surtout comme autorité en matière d'élégance et de bonnes mœurs (RAVEN 2004, XI, 175a-176b).

5. À propos du raffinement et des raffinés, voir : MONTGOMERY 2004, XI, 460ab ; ENDERWITZ 1989, p. 125-142 ; GIFFEN II, 1989, p. 821-822.

6. Al-Raffā', al-Muhibb wa-l-maḩbūb wa-l-mašmūm wa-l-mašrūb. Al-Sarī b. Ahmad al-Raffā' est un poète de l'époque abbasside qui, grâce à son talent, eut accès à la cour des Hiamdānides. Il écrivit des panégyriques et des satires et se distingua dans la description (wașf) (SEIDENSTICKER 1989a, II, p. 690). 
poétique contenant essentiellement des poèmes d'amour, des vers concernant des fleurs et des plantes aromatiques et de la poésie bachique ${ }^{7}$. Organisé par thèmes (ma'ānī), il fut conçu non seulement dans le but d'affiner le goût poétique de ses lecteurs, mais aussi dans celui d'enseigner les règles essentielles de la description aux apprentis poètes ${ }^{8}$.

Pour les pestilences, nous ferons principalement référence à la Hikāyat Abīl-Qāsim al-Bag̉dādī (L'histoire d'Abū al-Qāsim le Bagdadien) attribuée à Abū al-Muțahhar al-Azdī $\left(\mathrm{x}^{\mathrm{e}} \text { siècle }\right)^{9}$, dont l'édition la plus récente est parue sous le titre d'al-Risāla al-bag̀dādiyya (Épître bagdadienne) par Abū Ḥayyān al-Tawhīdī (m. 414/1023) ${ }^{10}$. Il relate la journée d'un écornifleur et pique-assiette de Bagdad qui s'invite dans une réunion de notables à Ispahan et décharge sur l'assistance son exceptionnelle verve. Afin d'entretenir le réalisme fictionnel de son récit, l'auteur lui-même affirme avoir rencontré Abū al-Qāsim à Bagdad et avoir été le témoin de l'éloquence par laquelle ce personnage représente, à lui seul, toutes les qualités, les défauts et les habitudes des Bagdadiens de son époque, au-delà de leurs différences de classe et de leur statut social ${ }^{11}$. Les Ahlāq al-wazīrayn ou Mațālib al-wazirayn (Satire des deux vizirs) d'al-Tawhìdī fournit également quelques renseignements sur la valeur morale que l'on attachait aux mauvaises odeurs ${ }^{12}$.

Ces quatre ouvrages ont été produits par les élites des régions centrales de l'empire abbasside et reflètent donc leurs goûts et leurs conceptions. Même dans le cas où la description concerne des couches plus basses de la société, comme dans certains passages d'al-Risāla al-baǵdādiyya, elle émane d'un groupe de privilégiés, seuls à pouvoir composer ce genre d'ouvrages ${ }^{13}$.

Dans un premier temps, nous concentrerons notre attention sur les parfums et les puanteurs qui se dégagent des hommes (ou des femmes), en définissant le contexte dans lequel ils sont mentionnés. Nous traiterons ensuite des odeurs dans la description des villes.

7. SADAN 1991, p. 68.

8. SADAN 1991, p. 73.

9. Nous n'avons pas beaucoup d'informations sur ce personnage qui vécut probablement au $\mathrm{V}^{\mathrm{e}} / \mathrm{XI}^{\mathrm{e}}$ siècle (GABRIELI 1960).

10. Abūal-Muțahhar, Hikāyat Abīl-Qāsim. En 1997, une nouvelle édition de la hikāya a été publiée sous le titre d'al-Risāla al-baġdādiyya. L'éditeur a attribué l'ouvrage à Abū Hayyān al-Tawhīīī: al-Tawhīīî, al-Risāla al-baġdādiyya. L'hypothèse qu'Abū Ḥayyān al-Tawhīīi ait rédigé la Hịkāyat Abīl-Qāsim sous le pseudonyme d'Abū al-Muṭahhar al-Azdī fut formulée pour la première fois par M.Gं'Ağīl. Ce même auteur explique, dans un article de 1987 intitulé «Hikāyat Abīl-Qāsim al-Bag̉dādī wa-l-Buwāyhiyyīn », que la richesse lexicale et linguistique de la Hikāya ne peut provenir que de la plume d'al-Tawhīì̄. De plus, le milieu social auquel appartient Abū al-Qāsim correspondrait exactement à celui d'al-Tawhīì̄. Une section entière de la Hikāya est prise du Kitāb al-Imtā wa-l-mu'ānasa d'al-Tawhīì̄. Voir 'AĞĪL 1987, p. 60-65. Concernant cette question, voir aussi BALDA 2000, p. 27-38. Bien que nous ne considérions pas ces arguments comme probants, nous donnerons en notes les références de l'édition de 1997.

11. Al-Tawhīì̄i, al-Risāla al-bag̀dādiyya, p. 42-43.

12. Abū Ḥayyān al-Tawḥīīi est un homme de lettres et prosateur du V ${ }^{\mathrm{e}} / \mathrm{XI}^{\mathrm{e}} \mathrm{s}$. (STERN 1960).

13. Dans son essai sur le muğūn, Zoltan Szombathy remarque que ce type de littérature, dont la Risāla fait sans doute partie, est produit par des hommes de lettres cultivés et appartenant aux classes sociales les plus élevées (SZOMBATHY 2013, p. 34). 


\section{Raffinement et art de se parfumer}

Dans l'imaginaire occidental, l'Orient apparaît depuis l'Antiquité comme l'origine des parfums les plus exquis. Les résines comme la myrrhe, l'encens et le storax, utilisées pour confectionner des parfums et des médicaments comme pour traiter les blessures, étaient récoltées en Arabie et acheminées vers l'Occident. Le baume de Mațariyya en Égypte, considéré comme la panacée, médicament capable de soigner tous types de maladies, ainsi que les blessures et les morsures venimeuses, était très recherché. Le chroniqueur égyptien Ibn Iyās (m. environ 1523) affirme qu'il était vendu, à son époque, à prix d'or ${ }^{14}$. La grande variété de plantes et d'arbres odoriférants mentionnés dans les ouvrages de botanique en langue arabe produits dans l'Espagne moresque $\mathrm{du} \mathrm{VI} / \mathrm{e} \mathrm{XI}^{\mathrm{e}}$ siècle, comme le Kitāb al-Filāḥa (Traité d'agriculture) d'Abū al-Hayr (m. début du VI $\mathrm{I}^{\mathrm{e}} / \mathrm{XII}$ e siècle), montre également que l'art du jardinage était plus développé dans les zones occupées par les Arabes que dans le reste de l'Europe occidentale ${ }^{15}$.

\section{Parfums pour toute circonstance}

Dans la partie du Kitāb al-Muwaššā intitulée Sunan al-z̧arf (Règles du raffinement), spécialement consacrée aux préceptes que tout raffiné doit suivre, aussi bien en matière de tenues vestimentaires que de comportements en société et de bonnes manières de table, un paragraphe est consacré aux parfums que les hommes raffinés et les femmes doivent ou ne doivent pas utiliser, comme son titre même le spécifie. Ce paragraphe est considéré comme essentiel par l'auteur de l'ouvrage, car celui qui ne respecte pas ces règles ne peut être un véritable raffiné (Bāb ziyyi-him fì l-ta'ațtur wa-l-țīb allad̄i man hāalafa-hu kāna gayr musīib) ${ }^{16}$. Une liste des parfums adaptés à chaque circonstance et à chaque individu représente l'essentiel de ce paragraphe.

Le musc

Le musc, dérivé de sécrétions produites par les mâles des cerfs musqués vivant en Asie centrale, mérite une attention particulière ${ }^{17}$. Bien qu'il ne soit pas originaire d'Arabie, il est mentionné dans la poésie préislamique et des débuts de l'islam, dans le Coran et dans le hadīt. Il est présent dans la poésie érotique où il était considéré comme un aphrodisiaque ${ }^{18}$.

Le Kitāb al-Muwaššā préconise de l'utiliser dépouillé de son écorce et dissous dans l'eau de rose (al-misk al-mashūul bi-mā' al-ward al-maḥlūl) ${ }^{19}$. Dans le Kitāb al-Muhibb, le musc est mentionné 74 fois, en vers comme en prose. Tout d'abord il est comparé « à la trace laissée

\footnotetext{
14. MiLWRIGHT 2003, p. 193.

15. HARVEY 1993, p. 118.

16. Al-Waššā', Kitāb al-Muwaššā, p. 162.

17. KING 2008, p. 178.

18. KING 2008, p. 175.

19. Al-Waššā', Kitāb al-Muwaššā, p. 162.
} 
par le musc sur une douce joue arrondie ${ }^{20}$. Un paragraphe entier lui est consacré dans le Kitāb al-mašmūm, dans lequel l'étymologie de son nom (ar. misk) est expliquée à partir de la racine MSK (serrer, retenir), car le cerf musqué le garde serré dans une poche de son ventre (yamsiku-hu al-ǵazāl fì surrati-hi) ${ }^{21}$. La couleur du musc se situe entre le noir (dukna) et le rouge (humra) et ces nuances sont utilisées dans la description de la bien-aimée ${ }^{22}$. Al-Sarī al-Raffā' rapporte aussi un hadīt prophétique selon lequel les gens du Paradis n'urinent ni ne vont à la selle, mais leur sueur coule sur leurs membres comme du musc ${ }^{23}$.

Nombre de poètes ont mentionné le parfum du musc qui, parfois couplé avec celui de l'ambre, se dégage des cheveux, de la bouche, des joues, du corps et des vêtements de la bien-aimée, et se répand comme s'il était porté par la brise printanière lorsqu'elle se lève ou rentre dans une pièce ${ }^{24}$. Il imprègne une demeure et évoque le souvenir de la rencontre amoureuse ${ }^{25}$. Son odeur est comparée à celle de la violette, du šāhisfaram (sic) et de l'orange amère (naranğ) ${ }^{26}$. De la terre émane parfois une fragrance comparable à celle de l'eau de rose lorsqu'elle est versée sur le musc ${ }^{27}$. Ce dernier peut en effet servir d'encens, quelquefois mélangé au camphre, et répandu sur les cendres ${ }^{28}$. Le vin exhale une exquise senteur de musc ${ }^{29}$.

Dans l'introduction du Kitāb al-Mašmūm, cette essence est également évoquée pour sa couleur et comparée ensuite au teint de l'aimée ou la brillance du vin dans une coupe ${ }^{30}$; dans une belle image, enfin, les lèvres et les dents de la bien-aimée sont comparées à des sceaux de musc imprimés sur des perles ${ }^{31}$.

20. Al-Raffä', Kitāb al-Muhibb, III, p. 7.

21. Al-Raffā', Kitāb al-Muhibb, III, p. 139.

22. Al-Raffä', Kitāb al-Muhibb, III, p. 154.

23. Al-Raffā', Kitāb al-Muhibb, III, p. 153.

24. Al-Mutanabbī (m. 354/965), Kitäb al-Muhibb, p. 26.; D̄ū l-Rumma (m. 117/735), Kitäb al-Muhibb, p. 27 et p. 126 ; al-Aqra' b. Mu'ād ( ${ }^{e r} / \mathrm{VII}^{\mathrm{e}}$ siècle), Kitāb al-Muhibb, p. 127 ; Ibn Mayyāda (m. entre 136/753 et 146/763), Kitāb al-Muhibb, p. 142 ; Ibn al-Rūmī (m. 376/896), Kitāb al-Mašmūm, p. 84 ; Ġaylān b. Hurayt al-Rāğiz (II'/VIII siècle), Kitāb al-Mašmūm, p. 174; al-A šā (8/629), Kitāb al-Mašmūm, p. 155 et p. 178; al-Marrār (m. à la fin de l'époque omeyyade), Kitāb al-Mašmūm, p. 173 ; al-Ṣanawbarī (m. 334/945), Kitāb al-Mašmūm, p. 26 et p. 175.

25. Abū 'Alī Da'bal (236/860), Kitāb al-Mašmūm, p. 163 ; Ibn al-Mu'tazz (m. 295/908), Kitāb al-Mahbūb, p. 79 ; Baššār b. Burd (m. environ 167/784) compare également sa relation avec sa bien-aimée au musc, à l'ambre et à la rose, Kitāb al-Muhibb, p. 224.

26. Al-Muhallabī (m. 352/963), Kitāb al-Mašmūm, p. 87 ; poète anonyme, Kitāb al-Mašmūm, p.110; Ibn Lankak (m. 360/970), Kitāb al-Mašmūm, p. 116.

27. Abū 'Uyayna (m. 170/809), Kitāb al-Mašmūm, p. 157.

28. Al-Rā'ì (95 ou 96/714 ou 715), Kitāb al-Mašmūm, p. 161 ; Ibn Qays al-Ruqayyāt (85/704), Kitāb al-Mašmūm, p. 162 ; al-'Arğ̄i (m. environ 120/738), Kitāb al-Mašmūm, p. 173.

29. Abū Nuwās (m. 198/814), Kitāb al-Mašrūb, p. 160 ; Yazīd b. Mu'āwiya (m. 63/683), Kitāb al-Mašrūb, p. 20.

30. Anonyme, Kitāb al-Mašmūm, p. 15; Ibn Tațriyya (m. 126/744), Kitāb al-Muhibb, p. 272; Abū Ḥafș al-Šațranǧ̄̄ (m. environ 210/825), Kitāb al-Muhibb, p. 220 ; al-Ṣanawbarī, Kitāb al-Muhibb, p. 221 ; al-Ṭā'î̀ (m. 231/846).

31. Kušăğim (m. environ 360/970-971), Kitāb al-Muhibb, p. 130 ; D̄ū l-Rumma, Kitāb al-Muhibb, p. 135. 
Vingt-quatre poètes ayant vécu entre le $\mathrm{I}^{\mathrm{er}} / \mathrm{VII}^{\mathrm{e}}$ et le $\mathrm{IV}^{\mathrm{e}} / \mathrm{X}^{\mathrm{e}}$ siècle font référence dans leurs vers au misk. Le musc était un topos répandu dans la description de la beauté naturelle ou humaine la plus exquise, que l'on fasse référence à son parfum, ou qu'on décrive sa couleur ${ }^{32}$.

Autres parfums « licites»

Quatre autres préparations odoriférantes sont admises à l'usage des raffinés en toute circonstance :

1. Le bâtonnet d'agalloche parfumé d'ambre recouvert d'eau de girofle (wa-isti'māl al-'ūd al-mu'anbar bi-mä' al-qurunful al-muhammal) ${ }^{33}$;

2. L'ambre gris du sultan (al-nadd al-sulțānī);

3. L'ambre de mer (al-'anbar al-bahrānì) ;

4. Le safran délayé dans un parfum composé d'aromates (al-'abīr wa-l-darāìir al-maftūqa bi-l-'abāirir).

Le Kitāb al-Muhibb explique que le 'ūd est une racine, mais ne mentionne pas al-'ūd al-mu'anbar ${ }^{34}$. Dans un paragraphe du Kitāb al-Mašmūm consacré au nadd, al-Sarī al-Raffā' précise qu'il est fabriqué artificiellement (mașnū' ġayr mah̆lūq) à partir d'un bâtonnet de bois d'aloès trempé dans un mélange de musc, d'ambre et de saule d'Égypte (al-bān $)^{35}$. Parfum rare et précieux, il fut conçu pour la première fois à l'intention du calife al-Wātiq (r. 227/842-232/847) ${ }^{36}$. Quant à l'ambre de mer, al-Sarī al-Raffā' affirme que l'origine du terme 'anbar est incertaine et qu'il est de couleur jaune ${ }^{37}$. En poésie, on fait référence à l'ambre à la fois pour sa couleur dorée et pour son parfum. Les poètes al-Marrār et Abū Nuwās mentionnent ces deux qualités lorsque l'ambre est associé au musc, et assimilent sa couleur jaune à celle de la lune et à celle du vin lorsqu'il est versé dans une coupe ${ }^{38}$. Le même Abū Nuwās et le poète antéislamique Ibn al-Ra'ā' al-Ġassānī ${ }^{39}$ comparent le parfum de l'ambre à l'haleine de leurs bien-aimées ${ }^{40}$. Al-Buhturī (m. 284/897) et al-Tanūhī (m. 384/994) rapprochent cette fragrance de celle apportée à leurs narines par la brise qui souffle sur le campement de l'aimée ${ }^{41}$. Le terme 'abīr, synonyme de safran (záfarān), est utilisé quant à lui uniquement en rapport à sa couleur ${ }^{42}$.

32. Le musc possède également une portée eschatologique, confirmée par le Coran. Dans la sourate des Fraudeurs, 83, 25-26, il est écrit qu' « un vin rare, cacheté par un cachet de musc » sera donné à boire aux purs qui iront au Paradis. Voir Coran, trad. D. Masson. Voir également QIAN 2008, p. 311.

33. Al-Waššā', Kitāb al-Muwaššā, p. 162.

34. Al-Raffā', Kitāb al-Muhibb, III, p. 143-144.

35. Al-Raffā', Kitāb al-Muhibb, III, p. 146.

36. BESSARD 2008, p. 119.

37. Al-Raffā', Kitāb al-Muhibb, III, p. 141.

38. Al-Raffā', Kitāb al-Muhibb, III, p. 173 et IV, p. 158.

39. Les dates de mort de ce poète de l'époque préislamique sont inconnues.

40. Al-Raffā', Kitāb al-Muhibb, III, p. 174 et III, p. 180. Concernant al-Ġassānī, voir Ziriklī IV, p. 220.

41. Al-Raffā', Kitāb al-Muhibb, III, p. 182 et III, p. 136.

42. Al-Raffā', Kitāb al-Muhibb, III, p. 184. 
Les préparations odoriférantes que nous avons mentionnées ci-dessus sont composées, à une exception près, à partir des cinq substances aromatiques que le médecin Ibn Māsawayh (m. 284/857), qui exerçait à la cour des Abbassides, affirme être la base (al-ușūl) de l'art de la parfumerie : le musc (al-misk), l'ambre gris ('anbar), le bois d'aloès ('üd), le camphre (kāfür) et le safran (záfarān) ${ }^{43}$. Ces parfums étaient considérés comme supérieurs aux autres. Il est même possible que leur mention dans la poésie ait eu une influence sur les écrits "scientifiques " ${ }^{44}$. Quoi qu'il en soit, ce sont des fragrances exquises, chères, qui demandent du savoir-faire dans leur préparation et représentent un marqueur social. Il n'est en effet pas donné à tous de s'en parfumer.

\section{Des parfums interdits}

Il est interdit aux personnes raffinées (zurafāa) de recourir à d'autres parfums que le musc, l'ambre, l'agalloche et le safran. Al-Waššă' explique les raisons de cette interdiction.

Le camphre (al-kāfür) est trop « froid » et l'on ne peut s'en parfumer que s'il fait très chaud, en cas de besoin impératif, ou lorsqu'on le met sur des braises en le mélangeant au musc et au safran. Ainsi préparé, il est excellent. L'interdiction faite aux zurafā de se parfumer au camphre est la seule qui relève de la théorie médicale arabe médiévale, selon laquelle la bonne santé de l'individu est assurée par un mélange tempéré et équilibré des quatre humeurs qui règlent le bon fonctionnement du corps humain ${ }^{45}$. La barmakiyya et les parfums similaires sont des fragrances interdites, car employées par les vauriens (al-mutaqallitūn) ${ }^{46}$. L'onguent de hulūq (à base de safran) ne convient pas non plus aux raffinés, car c'est un parfum de femme. La gaălia, décrite dans un paragraphe du Kitāb al-mašmūm qui lui est entièrement consacré, est une substance noire composée de musc, d'ambre et autres aromates et généralement employée comme cosmétique pour les cheveux ${ }^{47}$. Son usage est défendu, car c'est un parfum adapté aux jeunes garçons (șibyān) et aux femmes esclaves $\left(i m \vec{a}^{\prime}\right)^{48}$. Enfin, l'utilisation du dafir (un type de musc à l'odeur très forte) est déconseillée, car il laisse des traces de couleur sur la peau et sur les vêtements. Le Prophète aurait en effet recommandé que la vue soit dissociée de l'odorat dans la toilette

\footnotetext{
43. KING 2008, p. 175.

44. KING 2008, p. 178.

45. À ce propos voir BIESTERFELDT et GUTAS 1984, p. 21-55.

46. La barmakiyya est le résultat de la combinaison d'arbres à essences avec des épices et des aromates et elle était fréquemment utilisée dans les hammams au II $/ \mathrm{VIII}^{\mathrm{e}}$ et $\mathrm{III}^{\mathrm{e}} / \mathrm{IX}^{\mathrm{e}}$ siècles. Il s'agissait donc bien d'un parfum communément utilisé et non réservé aux uniques élites (BESSARD 2008, p. 119).

47. Al-Raffā', Kitāb al-Muhibb, III, p. 146-152.

48. La gālia aussi était un parfum communément utilisé dans les bains (BESSARD 2008, p. 119). Voir à ce propos l'article de Thierry Buquet dans ce volume (BUQUET 2015, p. 116), qui mentionne que la ġāliya est un « mélange d'ambre, de musc et d'encens, cité dans la poésie antéislamique. Al-Nuwayrī a compilé au XIV ${ }^{e}$ siècle plusieurs recettes de $\dot{g} a \bar{l}$ liya (...) ».
} 
des hommes et qu'une fragrance qui tache ne soit utilisée que sur les cheveux, là où sa trace n'est pas visible ${ }^{49}$.

Les femmes raffinées peuvent s'asperger, en plus des parfums qui leur sont propres, de tous ceux qui conviennent aux hommes. Parmi les fragrances licites figurent le lahāăh (sic), le santal, le șayyāh (eau parfumée utilisée pour se laver), le girofle (qurunful), la sāhiriyya (sic), le adqāl (sic). Elles peuvent aussi se parfumer avec des pâtes odoriférantes ( ma '̌̆̌unāt) et du safran, du hulūq ou du camphre. Il leur convient également de faire usage d'huiles parfumées comme la barmakiyya sultanienne, l'huile de violette (al-banafsağ) ou le vif-argent (zi'baq) ${ }^{50}$.

Quelques lignes plus bas, l'auteur insiste sur le fait que les fragrances qu'il a mentionnées ne sont autorisées qu'aux femmes, alors qu'elles sont formellement interdites aux hommes.

Cette liste commentée de parfums « licites » et «illicites » montre que, dans le code de raffinement du Kitāb al-Muwaššă, les individus sont reconnaissables à leur odeur. Les odeurs, comme les vêtements, les chaussures et les bijoux (à chacun desquels al-Waššā' consacre un paragraphe plus ou moins long), caractérisent l'être raffiné et sont donc un élément essentiel pour déterminer l'appartenance sociale et le genre d'un individu.

Certains parfums sont considérés comme « socialement inférieurs », car les esclaves, hommes et femmes, y ont recours. D'autres, comme la barmakiyya, renseignent sur la valeur des hommes qui les portent. Les femmes, enfin, peuvent s'asperger de toute essence, sans restrictions, alors que seuls certains parfums sont considérés comme virils et adaptés aux hommes.

Dans le cas des raffinés, les parfums sont donc un élément essentiel de l'esthétique de vie omni-compréhensive qui leur est prescrite.

\section{De ceux qui « ne sentent pas la rose »}

Si les fragrances constituent le symbole d'un statut social élevé, car l'art de se parfumer revêt une dimension à la fois esthétique et morale, les mauvaises odeurs sont au contraire associées à tout ce qui est bas, laid et vil.

\section{Abū al-Q̄̄sim}

La Risāla al-baǵdādiyya s'ouvre sur une accumulation d'adjectifs et d'attributs décrivant Abū al-Qāsim, son personnage principal ${ }^{51}$. Si ses qualités sont parfois contradictoires, les aspects négatifs prévalent néanmoins sur les traits positifs. Comme les autres sens, l'odorat est mis à contribution dans cette description exhaustive. Bien que l'auteur-narrateur lui

\footnotetext{
49. Al-Waššā', Kitāb al-Muwaššā, p. 162-163.

50. Al-Waššā', Kitāb al-Muwaššā, p. 164-165.

51. BALDA 2000, p. 374-382.
} 
attribue la qualité de zarîf (raffiné) ${ }^{52}$, Abū al-Qāsim ne ressemble guère aux raffinés dont nous avons décrit ci-dessus les habitudes en matière de cosmétique.

Ce personnage est ainsi qualifié ${ }^{53}$ :

1. Plus pourri que la fange des poissonniers (ašham min țin al-sammākin);

2. Plus fétide que l'odeur des tanneurs de cuir (antan min rịh al-dabbägiñn);

3. Un tas de déchets dans la corbeille d'un chiffonnier (dağra min șann qammāš);

4. Une ordure sur une poubelle (kuba 'alā mazbala);

5. Plus nuisible que le fromage avancé en âge (adarr min al-ğibn al-'atīa);

6. Plus infect que les rats (afsad min al-ğurd̄ān).

Les pestilences évoquées dans ce passage peuvent être classées en deux catégories. La première comprend celles qui se dégagent de la boue des poissonniers, des cuves des tanneurs et des déchets des chiffonniers. Ces relents évoquent des professions considérées comme malodorantes et socialement dévalorisées pour cette raison.

Dans la deuxième catégorie apparaissent d'autres effluves désagréables qui évoquent la nourriture avariée et renvoient aux mauvaises mœurs d'Abū al-Qāsim.

Les membres du mağlis d'Ispahan

Après avoir fait semblant de prier et de réciter nombre de versets coraniques, Abū al-Qāsim s'attaque aux membres de l'assemblée et décharge sur eux son éloquence ordurière. Ces personnages appartiennent à l'élite des notables d'Ispahan et jouent un rôle important dans l'administration de l'État. Néanmoins, l'éloquence d'Abū al-Qāsim et son inventivité dans la création des insultes les plus grossières, loin d'être inhibée par la puissance de ces personnages, en est au contraire redoublée. Parmi les cinq sens, la verve de ce personnage privilégie l'odorat puis la vue. L'ouïe n'intervient que lorsqu'Abū al-Qāsim décrit un joueur de tambour, et le goût est à peine évoqué lorsqu'il parle de mets pour lesquels un homme qui se donne des airs d'ascète irait jusqu'en Chine. Le toucher est totalement absent de cette diatribe.

Le secrétaire de chancellerie

À propos d'un secrétaire de chancellerie très puissant, Abū al-Qāsim affirme qu'il gère les affaires de l'État par des vents et qu'il « ne peut s'asseoir en tailleur sur un coussin sans laisser une vesse. ${ }^{54}$ » Lorsqu'ensuite on fait remarquer à notre orateur que le secrétaire en question possède une écriture parfaite et de l'éloquence, il réplique qu'« il parfume ses doigts avec le suc épais (sulh) dont les juifs enduisent les outres à beurre, ou mieux, avec la crotte d'un chien noir. Il faut qu'il se parfume aux vents des bains publics [...], ou bien

52. Le terme zarîf apparaît en effet parmi les adjectifs et attributs qui décrivent ce personnage, immédiatement suivi par son contraire, sah̆îf, vulgaire (al-Tawhịīī, al-Risāla al-baġdādiyya, p. 47).

53. Al-Tawhīì̄î, al-Risāla al-baġdādiyya, p. 49-50.

54. Cette traduction, comme certaines de celles qui suivent, sont en partie inspirées de celles de Réné Khawam, p. 35 . 
qu'il s'introduise dans le vagin d'une vache qui broute du fumeterre. ${ }^{55}$ » Enfin, lorsque les membres de l'assemblée recommandent à Abū al-Qāsim de prendre garde, car l'homme qu'il est en train d'insulter est puissant, cela redouble sa virulence : « C'est la trésorière Umm Mūsā, chargée de la fiente du poulailler ! C'est l'intendant du rivage qui garde les excréments de canard. ${ }^{56}$ "

Dans Ahlāq al-wazìrayn, qui a été rédigé pour assurer «la vengeance d'un déçu du mécénat, appelé à la cour de princes avides de reconnaissance et qui s'estima sous-utilisé au regard de ses compétences, humilié et mal payé ${ }^{57}$ ", l'auteur justifie la démarche qu'il a adoptée avec sa satire de vizirs, mentionnant d'autres exemples d'épîtres critiquant les puissants de ce monde. Dans ces écrits satiriques, l'odorat est mis à contribution pour les discréditer: "Ceci sans compter la souillure de votre mise, la repoussante saleté de vos mains et la puanteur que vous exhalez. ${ }^{58}$ » La venue au monde de la personne visée est aussi évoquée en termes scatologiques : «Vous êtes sans doute issu de quelque excrément fécondé par défécation [...]. Que Dieu maudisse cette double puanteur : deux poils de cul se sont frottés pour l'engendrer. ${ }^{59}$ » Enfin, la corruption et le mensonge qui apparaissent dans les dires de ce puissant personnage en ont fait « un envieux à l'haleine fétide, un sycophante à l'odeur putride. ${ }^{60}$ "

Dans ces descriptions, les mauvaises odeurs et les images repoussantes servent d'un côté à montrer que les personnages en question abusent de leur pouvoir, et de l'autre qu'ils ne sont pas dignes, à cause de leur bassesse morale et de leurs origines douteuses, d'exercer la charge dont ils sont investis. Elles visent à les rabaisser et à remettre en question leur valeur, en tant que personnes et comme agents de l'État. Les mauvaises odeurs contribuent de cette manière à façonner l'image comique et caricaturale d'un représentant du pouvoir en place. Elles véhiculent ainsi une critique à son égard et une attaque de l'institution qu'il représente.

Le soufi glouton

L'évocation des puanteurs ne sert pas seulement à railler le pouvoir politique, mais également à satiriser le milieu des hommes de religion. Après s'être épanché sur le secrétaire de chancellerie, c'est au tour de l'un des convives vêtu de laine grossière lui donnant des airs de soufi, d'être la victime de la verve d'Abū al-Qāsim. De l'avis de ce dernier, l'apparence du saint homme est trompeuse, car au lieu de conduire une vie d'ascète, détaché des biens de ce bas monde, il ne pense en réalité qu'à manger aux dépens des autres, au point qu'il se prostituerait pour humer le fumet d'une cuisine. Loin de cultiver un contact privilégié

\footnotetext{
55. Al-Tawhidi, al-Risāla al-baġdādiyya, éd. 'A. aš-Šāliǧ̄i, Manšūrāt al-Ǧamal, p. 60 et trad., p. 36.

56. Al-Tawhī̄ī̄, al-Risāla al-baġdādiyya, éd. 'A. aš-Šāliǧ̄̄, Manšūrāt al-Ǧamal, p. 60-61 et trad., p. 37.

57. Al-Tawhīì̄ì, Ahlāq al-wazìrayn, trad. p. 10.

58. Al-Tawhīì̄i, Ahlāq al-wazìrayn, p. 60 et trad., p. 54.

59. Al-Tawhīì̄i, Ahlā q al-wazìrayn, p. 63 et trad., p. 56.

60. Al-Tawhīì̄i, Ahlāq al-wazìrayn, p. 64 et trad., p. 59.
} 
avec Dieu à travers des pratiques mystiques, c'est dans le domaine des marmites qu'il est capable de distinguer l'invisible. En inversant le dire du Prophète qui prescrit aux musulmans de chercher la science où elle se trouve, fut-elle en Chine, Abū al-Qāsim déclare que cet homme, afin de dénicher une marmite, irait jusqu'au fin fond de l'empire byzantin, se trouverait-il en Chine ${ }^{61}$. Cette fois-ci, ce sont les bonnes odeurs de cuisine qui servent à fustiger l'hypocrisie de ce soufi, qui, malgré ses apparences d'ascète, ne pense en réalité qu'à se remplir le ventre.

Un homme raffiné

Un homme qui se donne des allures de raffiné est fustigé «à coup de nez » pour sa vantardise. Abū al-Qāsim le traite de pot de chambre de Damas, de sexe de chien macérant depuis soixante-dix ans dans du lait souillé au fond d'une latrine, et d'étron de chien abandonné sur une poubelle et trempé dans l'urine d'une chienne ${ }^{62}$. Les insultes qu'Abū al-Qāsim adresse à cet homme raffiné sont totalement opposées aux valeurs du raffinement. Alors que les raffinés sont censés, selon le Kitāb al-Muwašš $\bar{a}$, respecter une hygiène de vie stricte, basée sur la propreté et sur un régime alimentaire particulier, le héros de la Risāla évoque, dans la description de ce convive, tout ce qu'il y a de plus sale et de plus répugnant. Ici aussi on entrevoit la portée critique des invectives prononcées par Abū al-Qāsim contre ces notables qui cachent leurs vices sous une belle apparence extérieure et oublient que le code du zarf réside aussi et surtout, dans des mœurs nobles et dans une conduite de vie irréprochable.

\section{Bagdad versus Ispahan}

L'évocation littéraire des fragrances et des pestilences ne sert pas seulement à définir les règles de comportement et à décrire les usages d'un groupe élitiste, ou, au contraire, à stigmatiser des hommes de pouvoir ou de religion : dans la Risāla, elle sert également à illustrer des querelles «de clocher ». Les odeurs sont en effet fondamentales dans la comparaison (munāzara, litt. « dispute, controverse ») entre les villes de Bagdad et d'Ispahan qui occupe la partie centrale de la Risāla. Abū al-Qāsim alterne les propos élogieux visant Bagdad, et ses habitants, et des propos dénigrant Ispahan.

\section{L'air et la terre}

Abū al-Qāsim fait l'éloge de sa ville natale, Bagdad, qu'il compare à un paradis sur terre, auquel il oppose Ispahan. La brise qui souffle sur la cité irakienne porte le parfum de l'ambre et la terre sur laquelle elle est bâtie est pétrie de musc ${ }^{63}$. À Bagdad, les pommiers

\footnotetext{
61. Al-Tawhīì̄, al-Risāla al-baġdādiyya, p. 63-65.

62. Al-Tawhīì̄, al-Risāla al-baġdādiyya, p. 69.

63. Al-Tawhīì̄i, al-Risāla al-bag̀dādiyya, p. 90-91.
} 
en fruit et le myrte embaument l'air de la nuit ; au matin, sa terre semble avoir été arrosée d'eau de rose. La rosée exhale du sol un parfum de camphre ${ }^{64}$.

À Ispahan, en revanche, on ne hume que la pestilence du fumier des écuries apportée par le vent. Ses rues ressemblent à des cloaques à ciel ouvert ${ }^{65}$. Selon l'interprétation qu'en donne Abū al-Qāsim, dont les ressources verbales paraissent intarissables, les noms persans que l'on attribue aux différents secteurs d'Ispahan témoignent également de sa saleté et des effluves fétides qui règnent sur cette ville. Les noms persans de ces quartiers peuvent être traduits en français par «fumier du jardin » (Sārmarana), « décharge d'immondices » (Kulmirāy), «barbe à pet » ou «celui qui vient lâcher un vent dans vos barbes » (Ad̄ār), « crotte desséchée » (Kūr Samān) et « barbe à crotte » (Kūršānn) ${ }^{66}$.

Alors que l'habileté des maîtres artisans de Bagdad est prodigieuse, le corps de métier le plus florissant à Ispahan est constitué par les éboueurs qui, dans les rues, empoisonnent les narines des passants et se battent pour revendre les excréments qu'ils ont amassés ${ }^{67}$. Ces passages montrent que la propreté d'une ville et le traitement de ses déchets étaient des valeurs importantes dans la société arabe aux $\mathrm{IV}^{\mathrm{e}} / \mathrm{X}^{\mathrm{e}}$ et $\mathrm{V}^{\mathrm{e}} / \mathrm{XI}^{\mathrm{e}}$ siècles et que la qualité « olfactive » de l'air dans un milieu urbain contribuait à en faire la réputation.

\section{Les habitants}

L'environnement olfactif d'une ville tient en grande partie aussi à ses habitants. De l'avis d'Abū al-Qāsim, nul dans Ispahan ne porte comme à Bagdad des vêtements faits d'étoffes précieuses en provenance des quatre coins de la Dār al-islām, que l'on dirait «mélangées d'ambre et tissées de lumière printanière. ${ }^{68}$ » En revanche, si l'on essorait la chemise d'un habitant d'Ispahan, on pourrait en tirer une jarre entière d'huile à l'odeur fétide, car leurs habits et leurs maisons sentent les bains publics ${ }^{69}$. Sur les marchés de la ville, on chercherait en vain des parfums exquis et des essences précieuses, dont les Bagdadiens se parfument et parfument leurs intérieurs, car les habitants d'Ispahan ignorent jusqu'à leur existence ${ }^{70}$.

Les mets de Bagdad sont sans comparaison avec ceux d'Ispahan ${ }^{71}$. À l'heure de desservir aussi, les fragrances sont très présentes dans la capitale irakienne, alors qu'à Ispahan - déclare Abū al-Qāsim, sans montrer le moindre respect pour ses hôtes - «tous vos potages puent comme les pets d'un fiévreux, ou les rots provoqués par un aliment

\footnotetext{
64. Al-Tawhīì̄ì, al-Risāla al-baġdādiyya, p. 109, 110 et 111 .

65. Al-Tawhīì̄, al-Risāla al-bag̀dādiyya, p. 91.

66. Al-Tawhīīì, al-Risāla al-baǵdādiyya, p. 93 et trad. p. 72-73.

67. Al-Tawhīì̄ì, al-Risāla al-baġdādiyya, p. 110

68. Al-Tawhīì̄î, al-Risāla al-bag̀dādiyya, p. 133.

69. Al-Tawhīì̄i, al-Risāla al-baġdādiyya, p. 150.

70. Al-Tawhīì̄î, al-Risāla al-bag̀dādiyya, p. 138-147.

71. Al-Tawḥīdī, al-Risāla al-baġdādiyya, p. 151-163.
} 
indigeste. ${ }^{72}$ » Enfin, alors que dans les rues de Bagdad on peut voir de superbes montures, qui n'ont rien à envier à celles qui sont chantées dans la poésie préislamique et reflètent l'image de leurs maîtres ${ }^{73}$, les canassons d'Ispahan contribuent avec leurs vents et leurs crottins à polluer l'air de la ville ${ }^{74}$.

Le discours d'Abū al-Qāsim vise clairement ici à critiquer le manque de raffinement des habitants d'Ispahan, qui, à la différence des Bagdadiens, ne se préoccupent ni de se procurer les produits les plus coûteux et les plus luxueux de l'époque, ni d'acheter des montures nobles et admirables, car leurs goûts sont vils et populaires.

Les esclaves chanteuses et les éphèbes

Le dernier élément de comparaison que nous avons choisi de présenter n'est pas des moindres. Les esclaves chanteuses et les éphèbes musiciens d'un cénacle représentent la richesse et le statut social élevé de leurs maîtres et « font et défont les réputations à leur gré et imposent une esthétique de l'existence, et un art de vivre et de dire l'amour. ${ }^{75}$ » Ils contribuent ainsi à créer la réputation d'une ville ou, du moins, celle de ses élites.

Dans la description de la qayna (esclave chanteuse) de Bagdad, Abū al-Qāsim reprend les topos poétiques traditionnels du gazal, que nous avons vu apparaitre dans la description de la femme chez al-Sarī al-Raffā' :
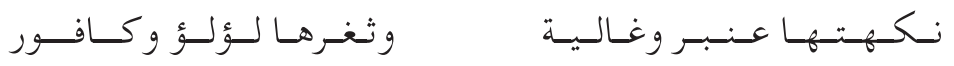

(Son haleine est ambre et gālia, sa bouche perles et camphre!) ${ }^{76}$

En prose aussi Abū al-Qāsim exalte le parfum qui se dégage de la qayna lorsqu'elle entre dans un salon ${ }^{77}$. Il n'en va pas de même pour l'esclave chanteuse d'Ispahan dont la salive, lorsqu'elle postillonne, empoisonne même les vipères et dont l'haleine fissure le sol ${ }^{78}$. Son orifice anal est comparé à une bouche d'égout sortant d'un mur en ruine ${ }^{79}$ et ses aisselles sentent l'oignon ${ }^{80}$, pour ne pas parler de sa sueur dont l'odeur est comparée à celle des excréments ${ }^{81}$. La liste des pestilences que dégage l'esclave chanteuse d'Ispahan sont plus nombreuses encore, mais nous nous limiterons à ces quelques exemples. Il en va de même pour l'échanson, dont l'image stéréotypée fixée après les $\mathrm{III}^{\mathrm{e}} / \mathrm{IX}^{\mathrm{e}}-\mathrm{IV} \mathrm{e} / \mathrm{X}^{\mathrm{e}}$ siècles comme celle

72. Al-Tawhīiñ, al-Risāla al-bag̀dādiyya, p. 167-168 et trad., p. 116 :

تفوح ريح الغضائر إذا قدّدت كريح فسا المحموم أو جشاء المتخوم

73. Al-Tawhīīì, al-Risāla al-baǵdādiyya, p. 114-127.

74. Al-Tawhīīi, al-Risāla al-bag̀dādiyya, p. 127-132.

75. CHEIKH-MOUSSA 2008, p. 98.

76. Al-Tawhīì̄, al-Risāla al-bag̀dādiyya, p. 195.

77. Al-Tawhīīī, al-Risāla al-bag̀dādiyya, p. 197.

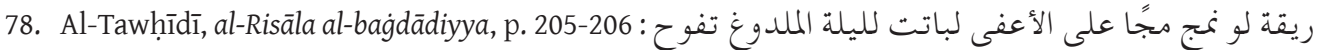

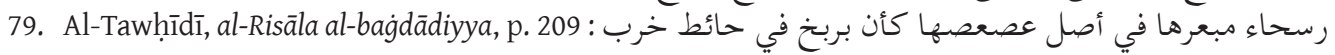

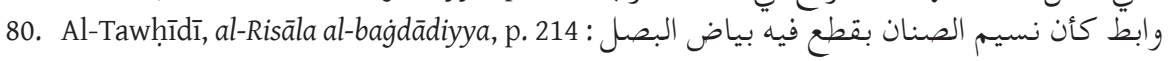

81. Al-Tawhīìī, al-Risāla al-bag̀dādiyya, p. 216. 
d'un jeune homme raffiné « au visage agréable, aux vêtements propres, sentant bon et ayant de bonnes manières ", se voit renversée ${ }^{82}$.

L'éloquence ordurière d'Abū al-Qāsim plonge ses racines dans les règles de bienséance et dans les codes du gazal, et agit comme un miroir déformant afin de dénoncer le mauvais goût littéraire des gens d'Isphahan ainsi que la vulgarité des plaisirs auxquels ils s'adonnent. Une revendication anti-shu'ūbite n'est également pas à exclure parmi les motivations de l'auteur ${ }^{83}$. Quoi qu'il en soit, les odeurs jouent un rôle essentiel dans la description de ces deux villes, qu'elles soient positives ou négatives. La liste des parfums de la ville de Bagdad et des pestilences d'Ispahan pourrait être allongée mais les exemples cités suffisent à montrer que l'extraordinaire éloquence d'Abū al-Qāsim, capable de s'exercer dans les domaines les plus différents, construit une sorte de géographie olfactive des milieux urbains. Même lorsqu'il s'agit de villes, l'odorat est mis à contribution dans la définition du raffinement et de la noblesse. Autrement dit, les odeurs que l'on respire dans une ville sont essentielles pour établir son rang, pour en faire l'éloge ou pour la rabaisser. Grâce à ce guide «touristique » des senteurs, même un aveugle serait capable de se repérer.

\section{Conclusion}

Que ce soit dans la description des personnes ou dans celle des villes, les odeurs, bonnes ou mauvaises, représentent un élément fondamental de la distinction sociale. Dans le Kitāb al-Muwaššă, bien qu'accompagné d'autres composantes, le parfum sert à déterminer la position sociale d'un individu dans la société et c'est en grande partie à l'odeur que l'on reconnaît le raffiné. L'odeur devient ainsi un code, un marqueur social, qui, au-delà des clichés littéraires, avait probablement pour fonction de permettre à chaque individu de revendiquer son appartenance sociale et son origine ou de stigmatiser celle de ceux qui sentaient différemment.

Au-delà du statut social de l'individu, les odeurs témoignent aussi des qualités morales. Alors que les bonnes mœurs " sentent bon », la pourriture morale transpire de l'individu et trouve son expression dans les pestilences qui émanent de son corps. Dans la littérature occidentale, la vilénie est plus associée à la laideur qu'à la puanteur ${ }^{84}$, et cette dernière indique plutôt une origine sociale modeste. En revanche, dans l'imaginaire social arabe médiéval, les odeurs reflètent également les mœurs et l'odorat contribue ainsi à créer une image complète de beauté ou de laideur, qui correspond à la pureté ou à la corruption morale.

\footnotetext{
82. CHEIKH-MOUSSA 2008, p. 102.

83. YASIR 2003, p. 60.

84. Nous pensons, par exemple, au Portrait de Dorian Gray d'Oscar Wilde.
} 


\section{Bibliographie}

\section{Sources}

Abū al-Muțahhar, Al-Azdī, Hiikāyat Abīl-Qāsim, éd. A. MEZ, Heidelberg, Carl Winter's Universitätbuchhandlung, 1902.

Al-Tawḥīī̄, Abū Ḥayyān, al-Risāla al-baġdādiyya, éd. 'A. AŠ-ŠĀLIǦī, Manšūūāt al-Ǧamāl, Beyrouth, 1997, trad. René KHAWAM, 24 heures de la vie d'une canaille, Paris, Phébus, 1998.

Al-Tawhịīī, Abū Ḥayyān, Aḥlāq al-wazīrayn, Beyrouth, éd. Dār Șādir, 1992 ; trad. Frédéric LAGRANGE, La satyre des deux vizirs, Paris, Sindbad Actes Sud, 2004.

Al-Sarī al-Raffā', al-Muhibb wa-l-maḥbūb wa-l-mašmūm wa-l-mašrūb, Damas, éd. Mațbū'āt mağma' al-lug̉a al-'arabiyya bi-Dimašq, 1986.

Al-Waššā', Kitāb al-Muwaššā, Beyrouth, éd. Dār Șādir, 1965.

\section{Références}

‘AĞīl M.Ǵ. 1987, « Hiikāyat Abī l-Qāsim al-Bag̉dādī wa l-Buwāyhiyīn », Afāq 'arabiyya, Bagdad, juin 1987.

BALDA Monica 2000, Le personnage d'Abū l-Qāsim dans la Hịkāyat Ab̄̄l-Qāsim d'Abū al-Muțahhar al-Azdī: portrait d'un écornifleur éloquent et contestataire, Mémoire de D.E.A. sous la direction de Katia ZAKHARIA, Université Lumière-Lyon II.

BALDA Monica 2003, «Marginalité et éloquence contestataire: le personnage d'Abū l-Qāsim dans la Hikāyat Abī l-Qāsim, d'Abū al-Muțahhar al-Azdī », in Cristina de la PUENTE (éd.), Identidades marginales, Madrid, CSIC (Estudios Onomasticos-biograficos de al-Andalus XIII), p. 370-393.

BESSARD Fanny 2008, «Pratiques sanitaires, produits d'hygiène et de soin dans les bains médiévaux (VIII /IX siècles) », Bulletin d'Études Orientales LVII, p. 111-125.

BIESTERFELDT Hans et GUTAS Dimitri 1984, "The malady of Love», Journal of the American Oriental Society 104/1, p. 21-55.

CHEIKH-MousSA Abdallah 2008, "Figures de l'échanson (sāqī) dans la littérature arabe médiévale », in Veronique Gely (éd.), Ganymède ou l'échanson. Rapt, ravissement et ivresse poétique, Paris, Presses universitaires de Paris ouest, p. 95-104.

CORBIN Alain 2008, Le miasme et la jonquille, Paris, Flammarion.

ENDERWITZ Susanne 1989, « Du fatā au zarīf », Arabica XXXVI, p. 125-142.

EVANS Suzanne 2002, « The scent of a martyr », Numen 49/2, p. 193-211.

GABRIELI Francesco 1960, « Abū l-Muțahhar al-Azdī», in Encyclopédie de l'Islam (2éd.), Suppl., 31a, Leyde, E.J. Brill.

GIFFEN Lois Anita 1989, "Zarf », in Julie Scott MeISAMI et Paul STARKY (éd.), in Encyclopaedia of Arabic Literature II, Londres, Routledge, p. 821-822.

HARVEY John H. 1993, « The book of Abü' l-Khayr », Garden History 21/1 (Summer 1993), p. 118-120.

IBN DĀNIYĀL Muhammad 2015, Three Shadows Plays, éd. Paul KAHLE, Oxford, Gibb Memorial Trust.

JACQUET Chantal 2010, Philosophie de l'odorat, Paris, PUF.

KING Anya 2008, «The Importance of Imported Aromatics in Arabic Culture: Illustrations from pre-Islamic and Early Islamic Poetry », Journal of Near Eastern Studies 67/1, p. 175-189. 
MiLWRIGHT Marcus 2003, «The balsam of Matariyya: An exploration of a Medieval panacea », Bulletin of the School of Oriental and African Studies 66/2, p. 193-209.

MONTGOMERY James 2004, « Zarîf », in Encyclopédie de l'Islam (2éd.), XI, 460ab, Leyde, E.J. Brill.

QIAN Ailin 2008, "Spice, Spiced Wine, and Pure Wine », Journal of the American Oriental Society 128/2, p. 311-316.

RAVEN Wim 2004, «al-Waššā’” », in Encyclopédie de l'Islam (2e éd.), XI, 175a-176b, Leyde, E.J. Brill.

SADAN Joseph 1991, "Maiden's Hair and Starry Skies », in Sasson SомEKH (éd.), Israel Oriental Studies, Studies in Medieval Arabic and Hebrew Poetics, E.J. Brill, Leyde, p. 57-90.

STERN Samuel Miklos 1960, «Abū Ḥayyān al-Tawhīì̄̄», in Encyclopédie de l'Islam (2éd.), I, 130a-131a, Leyde, E.J. Brill.

SEIDENSTICKER Tilman 1989a, « Al-Sarī al-Raffā’ », in Julie Scott MEISAMI et Paul STARKY (éd.), Encyclopaedia of Arabic Literature II, Londres, Routledge, p. 690.

SEIDENSTICKER Tilman 1989b, « Ibn Tatriyya », in Julie Scott MEISAMI et Paul STARKY (éd.), Encyclopaedia of Arabic Literature I, Londres, Routledge, p. 377.

SZOMBATHY Zoltan 2013, Mujūn, Libertinism in Medieval Muslim Society and Literature, Gibb Memorial Trust, Exeter.

VAN GELDER Geert Jan Henk 1989, « Ibn Lankak », in Julie Scott MEISAMI et Paul STARKY (éd.), Encyclopaedia of Arabic Literature I, Londres, Routledge, p. 347.

YASIR Suleiman 2003, The Arabic Language and National Identity: A Study on Ideology, Edinburg University Press, Édimbourg, Edinburg University Press.

ZIRIKLì Hayr al-Dīn 1977, al-A ‘ām, Beyrouth, Dār al-'ilm li l-malāyīn. 